\title{
Análise do tratamento térmico de austêmpera em uma liga de ferro nodular SAE J434 - D5504
}

\author{
Analysis of austemper heat treatment on ductile iron SAE J434 - D5504
}

\author{
Gustavo Emmanuel Carvalho Borella Guidetti ${ }^{1}$, Marcos Massao Shimano², Kempees de \\ Oliveira Andrade ${ }^{3}$
}

\begin{abstract}
${ }^{1}$ Professor do Departamento de Engenharia Mecânica - Universidade Federal do Triângulo Mineiro, Uberaba, Minas Gerais, Brasil. Orcid: 0000-0002-9054-5789. E-mail: gustavo.guidetti@uftm.edu.br

${ }^{2}$ Professor do Departamento de Engenharia Mecânica e do Programa de Mestrado Profissional em Inovação Tecnológica, Universidade Federal do Triângulo Mineiro, Uberaba, Minas Gerais, Brasil.

Orcid: 0000-0002-9276-2939. E-mail: marcos.shimano@uftm.edu.br

${ }^{3}$ Aluno do Programa de Mestrado Profissional em Inovação Tecnológica, Universidade Federal do Triângulo Mineiro, Uberaba, Minas Gerais, Brasil. E-mail: kempees@hotmail.com
\end{abstract}

\begin{abstract}
RESUMO: Ao submeter uma liga de ferro fundido nodular ao processo de austêmpera, buscou-se identificar o efeito desse tratamento através de análises das propriedades mecânicas e microestruturais sobre esse material, colaborando ativamente na parametrização dos processos para obtenção de melhorias no material pela empresa de fundição. Foram realizadas três fusões da liga de ferro fundido nodular da classe SAE J434 - D 5504 que resultaram em 24 corpos de prova. Os corpos de prova foram austenitizados a $900^{\circ} \mathrm{C}$ por duas horas e posteriormente austemperados na temperatura de $290^{\circ} \mathrm{C}$ por duas horas. Foram realizados ensaios de tração, dureza e impacto, além de análises metalográficas. As microestruturas analisadas apresentaram matriz ausferrítica, de forma homogênea ao longo de todos as amostras analisadas e como esperado, as propriedades mecânicas do ferro fundido nodular austemperado obtidas, chegaram a patamares significativamente melhores ao comparar com material bruto de fundição. Foi verificado um aumento de $95 \%$ no limite de resistência a tração, de $142 \%$ no escoamento, de $74 \%$ na dureza e $82 \%$ na resistência ao impacto.
\end{abstract}

Palavras-chave: ausferrita, austêmpera, ferro fundido nodular austemperado.

ABSTRACT: When submitting a nodular cast iron alloy to the austemper process, sought identify the effect of this treatment through analysis of the mechanical and microstructural properties on this material, actively collaborating in the parameterization of the processes to obtain improvements in the material by the foundry company. Three fusions of the SAE J434 - D 5504 nodular cast iron grade alloys were carried out, resulting in 24 specimens. The specimens were austenitized at $900^{\circ} \mathrm{C}$ for two hours and subsequently austempered at $290^{\circ} \mathrm{C}$ for two hours. Tensile, hardness and impact tests were carried out, as well as metallographic analysis. The microstructures analyzed showed ausferritic matrix, homogeneously throughout all the samples analyzed and, as expected, the mechanical properties of the austemperated nodular cast iron obtained, reached significantly better levels when compared with gross material. There was an increase of $95 \%$ in the limit of tensile strength, $142 \%$ in yield, $74 \%$ in hardness and $82 \%$ in impact resistance.

Keywords: ausferritic, austemper, austempered ductile iron. 


\section{INTRODUÇÃO}

A alta concorrência, a busca constante da melhoria de qualidade e a redução de custos de produção, forçam as empresas a buscarem estratégias cada vez mais eficientes e desafiadoras. Desafios esses, que impõem à engenharia a criação de materiais mais resistentes, leves e com menores custos de produção (NOGUEIRA, 2011).

No setor metalúrgico, as pesquisas visam o desenvolvimento de ligas e materiais que favoreçam a fabricação de peças e equipamentos com menores custos e com desempenhos iguais ou superiores. A busca da melhoria nas propriedades desses materiais é feita através da adição de elementos de liga ou por tratamentos térmicos, com critérios relacionados a parâmetros como carregamento mecânico, térmico, ou condições de contorno como custos de manufatura, reciclagem, aceitação do público e usinabilidade. (BUCHLI, 2010).

No Brasil, somente no ano de 2016, foram produzidas 111.939 toneladas de ferro fundido, o que corresponde a $80 \%$ do total de produção de fundidos no ano, dentre metais ferrosos e não ferrosos (ABIFA, 2017). É no contexto de destaque, dentro do percentual de produção nacional, que os ferros fundidos carecem de uma atenção especial com aspectos envolvidos na obtenção e processamento dos materiais de engenharia.

A necessidade de estudos a respeito do ferro fundido e as notáveis combinações de propriedades do Austempered Ductile Iron (ADI), conhecido também como ferro fundido nodular austemperado, têm motivado pesquisas na área. Sabe-se que este metal é composto por microestrutura com diversas combinações de propriedades fazendo com que este material seja utilizado na indústria em substituição a aços forjados, com elevada resistência mecânica, elevada ductilidade, inferior aos aços, porém superior a maioria dos ferros fundidos (CARMO, 2003).

$\mathrm{O}$ ADI difere do ferro fundido nodular pela introdução de elementos ligantes e por sofrer tratamento térmico. Possui uma matriz composta de ferrita acicular e austenita estável com elevado teor de carbono, a qual é responsável por melhoras significativas nas propriedades mecânicas do material obtida pelo processo de tratamento térmico conhecido como austêmpera (CARMO, 2003). Tratamento definido por Machado (2007, p.15) como "tratamento isotérmico, que aplicado ao ferro fundido nodular, incrementa as propriedades mecânicas e a tenacidade".

O ADI oferece altas: resistência mecânica a tração; resistência ao desgaste; tenacidade à fratura; ductilidade, em relação ao ferro nodular. Estas propriedades fazem com que o ferro nodular austemperado seja recomendado para muitas aplicações, como em componentes solicitados ao desgaste, que incluem peças de equipamentos de movimentação de terra e de mineração ou em componentes automobilísticos como é o caso de engrenagens de motores e peças estruturais de baixo peso (PIMENTEL; GUESSER, 2017). Ademais, "tem a vantagem de menor custo de matéria-prima, menor custo de produção, baixa densidade, usinabilidade variável e maior capacidade de amortecimento do que o aço-liga a substituir" (MARTINEZ, 2011, p.16).

É neste contexto, e considerando a necessidade de estudos a respeito do ADI na indústria de fundição, que esse trabalho visa submeter a liga de ferro fundido nodular ao processo de austêmpera, identificando o comportamento desse material através de análises das suas propriedades mecânicas e microestruturais, antes e após o tratamento térmico de austêmpera. 


\section{MATERIAL E MÉTODOS}

Foi estudada uma liga de ferro fundido nodular do tipo SAE J434 - D 5504 produzida pela Fundição Batatais, localizada na cidade de Batatais-SP. Os intervalos da composição química sugeridos na norma são amplos e não refinados. Desse modo, para atingir as propriedades da classe, faz-se o uso de elementos de liga de expertise da fundição. Porém, como o objetivo é analisar e verificar as alterações provocadas no ferro base após o tratamento térmico; utilizou-se como referência as faixas de valores de composição química sugerida pela norma ASTM A 897/A897M-16, que regulamenta o ADI e sugere as faixas de composição para se obter as condições próprias deste material, descritas na Tabela 1.

Tabela 1 - Composição química sugerida pela norma ASTM A 897/A897M-16

\begin{tabular}{clllllllll}
\hline $\mathbf{C}$ & $\mathrm{Si}$ & $\mathrm{Mg}$ & $\mathrm{Mn}$ & $\mathrm{Cu}$ & $\mathrm{Ni}$ & $\mathrm{Mo}$ & $\mathrm{P}$ & $\mathrm{S}$ & $\mathrm{Cr}$ \\
\hline $3,6 \pm 0,2 \%$ & $2,5 \pm 0,2 \%$ & $0,04 \pm 0,005 \%$ & $0,4 \pm 0,05 \%$ & $<0,8 \%$ & $<2 \%$ & $<0,3 \%$ & $<0,04 \%$ & $<0,02 \%$ & $<0,1 \%$ \\
\hline
\end{tabular}

Fonte: ASTM A 897/A897M-16, 2016

Os processos de análise metalográfica, ensaios de tração e dureza foram desenvolvidos nos laboratórios da Fundição Batatais, enquanto os ensaios de impacto foram realizados no laboratório de ensaios mecânicos da Universidade Federal do Triângulo Mineiro (UFTM). O processo de tratamento térmico de austêmpera foi realizado pela empresa Maxitrate, localizada na cidade de Araraquara-SP.

Para se analisar a influência da variabilidade da composição química e das diferenças de temperaturas foram feitas três fusões da mesma liga, contendo igual carga de composição representada na Tabela 2.

Tabela 2 - Composição da carga do forno

\begin{tabular}{cc}
\hline Material & Quantidade \\
\hline Ferro gusa $(\mathrm{kg})$ & $334 \pm 5$ \\
Retorno $(\mathrm{kg})$ & $345 \pm 5$ \\
Cavaco $(\mathrm{kg})$ & $21 \pm 2,5$ \\
Liga/panela $(\%)$ & 0,91 \\
Inoculante $(\%)$ & 0,5 \\
\hline Fonte: Fundição Batatais, 2018
\end{tabular}

As ligas foram fundidas em um forno de indução com capacidade nominal de $700 \mathrm{~kg}$. A temperatura do metal líquido ao final da etapa de fusão variou entre $1530^{\circ} \mathrm{C}$ a $1550^{\circ} \mathrm{C}$, sendo esta temperatura controlada com pirômetro de imersão. O processo de nodularização foi realizado por uma panela rotativa com capacidade de $150 \mathrm{~kg}$, equipada com quatro células de carga para pesagem do metal líquido. Foi utilizado no tratamento de nodularização, 0,91\% de liga nodulizante Fe-Si-Mg Elmag® 5837 nodulariser da marca Elkem, sobre o peso de metal líquido. Após o tratamento de nodulização, foi realizado o tratamento de inoculação no jato de transferência para as panelas de vazamento na proporção de 0,50\% de liga Fe-Si Foundrisil $\Theta^{\circ}$ inoculant da marca Elkem sobre o peso de metal. As características das ligas inoculante e nodulizante estão descritas na Tabela 3. 
Tabela 3 - Composição química (inoculante e nodulizante)

\begin{tabular}{llllllll}
\hline Inoculante - FeSi & & $\mathrm{Si}(\%)$ & $\mathrm{Ba}(\%)$ & $\mathrm{Mn}(\%)$ & $\mathrm{Ca}(\%)$ & $\mathrm{Al}(\%)$ & \\
\cline { 2 - 7 } & & 48,31 & 1,09 & 0,21 & 1,087 & 1,138 & \\
\hline Nodulizante - & $\mathrm{Mg}(\%)$ & $\mathrm{Si}(\%)$ & $\mathrm{Ca}(\%)$ & $\mathrm{Ce}(\%)$ & $\mathrm{MgO}(\%)$ & $\mathrm{Al}(\%)$ & Terras raras (\%) \\
FeSiMg & 5,78 & 45,5 & 0,96 & 0,63 & 0,09 & 0,9 & 1,03 \\
\hline
\end{tabular}

Fonte: Fundição Batatais, 2018

Após o tratamento de inoculação, foi realizado vazamento em oito moldes por panela, visando obter os corpos de prova tipo $\mathrm{Y}$ com espessura da parte útil de 25 milímetros, conforme ASTM A 897/A897M-16. Assim, foram fundidos 24 corpos de prova no total das três fusões. Com 8 (oito) corpos de prova para cada fusão, foram extraídas 4 amostras para cada ensaio no estado bruto de fusão e no austemperado. As temperaturas de vazamento foram medidas usando um pirômetro de imersão momentos antes do enchimento dos moldes, obtendo-se assim as temperaturas de vazamento dos moldes representadas na Tabela 4.

Tabela 4 - Temperatura de vazamento

\begin{tabular}{cc}
\hline Fusão & Temperatura \\
\hline 1 & $1391^{\circ} \mathrm{C}$ \\
2 & $1425^{\circ} \mathrm{C}$ \\
3 & $1395^{\circ} \mathrm{C}$ \\
\hline Fonte: Fundição Batatais, 2018
\end{tabular}

Durante o enchimento dos moldes foi retirada uma amostra do material líquido por fusão para análise de composição química, determinadas com o auxílio da metodologia de espectrometria de emissão óptica. No caso, utilizou-se um espectrômetro do tipo SPECTROLAB, no laboratório de análises da Fundição Batatais. De acordo com a norma ASTM A 897/A897M-16 o carbono equivalente é calculado pela Equação 1 e deve permanecer dentro do intervalo de 4,3 a 4,6 para seções de 13 a $51 \mathrm{~mm}$, valor esse atingido pelas ligas fundidas.

$$
\% C E=\% C+1 / 3(\% S i)+1 / 3(\% P)
$$

Para os testes do material austemperado, 12 corpos de prova do tipo $Y$, quatro correspondentes a cada fusão, foram enviados para tratamento térmico de austêmpera na empresa Maxitrate. A austenitização foi realizada em um forno tipo poço com atmosfera controlada. Após a etapa de austenitização, o material foi transferido para um forno com banhos de sais fundidos, também do tipo poço. As temperaturas em todas as etapas foram controladas por meio de termopares. Os dados de processos utilizados para obtenção dos corpos de provas austemperados foram fornecidos pela empresa que realizou o tratamento e estão descritos na Tabela 5.

Tabela 5 - Dados do ciclo térmico realizado

\begin{tabular}{lcc}
\hline Ciclo térmico & Temperatura $\left({ }^{\circ} \mathrm{C}\right)$ & Tempo $(\mathrm{h})$ \\
\hline Austenitização & $900 \pm 8$ & 2 \\
Austêmpera & 290 & 2 \\
\hline
\end{tabular}

Fonte: Maxitrate, 2018 
Os corpos de provas para ensaios de tração foram retirados da parte inferior dos blocos. Eles foram usinados com diâmetro reduzido de 9 milímetros em um comprimento útil de 45 milímetros, em concordância com a norma ASTM A897/A897M-16. Os ensaios foram realizados em uma máquina universal de ensaios modelo EMIC $^{\circledR}$ 23-200, com capacidade para $200 \mathrm{kN}$.

Para o ensaio de impacto Charpy, a usinagem dos corpos de prova seguiu as orientações da norma ASTM A327/A327M-11, com formatos retangulares sem entalhe. Os ensaios foram realizados na máquina de ensaio Charpy marca Equilam ${ }^{\circledR}$ - modelo EQIM300 com pêndulo de impacto com capacidade de 150 Joules no laboratório de ensaios mecânicos da UFTM.

As amostras para as análises de metalografia foram obtidas do corpo de prova de tração após os ensaios, a uma distância de 50 milímetros da extremidade. Para preparação das análises metalográficas, as amostras foram lixadas de forma sequencial com lixas nas granulometrias 120; 220; 400 e 600 mesh. O polimento foi feito com suspensão de alumina de $1 \mu \mathrm{m}$. $O$ ataque químico feito com uma solução de Nital a $2 \%$. Para a leitura das análises metalográficas, foram capturadas imagens das microestruturas com a câmera Olympus SC30 acoplada ao microscópio óptico Olympus GX41 em conjunto com o software de análise de imagem Stream Essentials ${ }^{\circledR}$. As imagens de microscopia óptica foram utilizadas para quantificar no estado bruto, o número de nódulos por unidade de área, o grau de nodularização, tamanho e tipo de grafita, constituição das microestruturas da matriz (ferrita/perlita), seguindo metodologias baseadas nas normas ASTM A247-17 e ASTM E407-07.

Os ensaios de dureza foram feitos com Durômetro do tipo Brinell $(\mathrm{HB})$ da marca Hoytom $^{\circledR}$, com uma esfera de tungstênio com $10 \mathrm{~mm}$ de diâmetro e carga de 3000 kgf, diretamente no bloco $\mathrm{Y}$, conforme norma ASTM A897/A897M-16 e descrição de método da norma ASTM E10-17. As medições foram realizadas nas superfícies das amostras, com determinação do diâmetro de impressão com auxílio de um leitor óptico, e com o uso do software Brinell Electron $\mathrm{RT}^{\circledR}$.

\section{RESULTADOS E DISCUSSÃO}

\section{Análise Química}

As composições das análises químicas das três fusões estão descritas na Tabela 6. De acordo com a composição sugerida pela norma ASTM A 897/A897M-16, citada na Tabela 1, as ligas apontaram valores próximos das faixas ideais. O silício apresentou valores pouco abaixo do índice inferior do intervalo sugerido, o que pode afetar no potencial de austemperabilidade do ferro fundido, pois segundo Hupalo, Balzer e Warmling (2006), o silício é responsável por aumentar a velocidade de difusão do carbono da ferrita para a austenita. Além disso, é um elemento com efeito grafitizante, inibidor da formação de bainita e em excesso, pode suprimir a formação de ausferrita.

Os valores dos elementos de liga, como $\mathrm{Cu}$, $\mathrm{Ni}$, Mo e Cr estão dentro do esperado. Vale salientar que a utilização do Cu em valores próximos ao limite recomendado, reforça a intenção do seu uso para aumentar a austemperabilidade do processo. Destaca-se ainda que, para valores excessivos, o Cu dificulta a difusão do carbono pois cria uma barreira em torno do nódulo de grafita. 
Tabela 6 - Composição química

\begin{tabular}{llllll}
\hline C.Q. & Fusão 1 (\%) & Fusão 2 (\%) & Fusão 3 (\%) & Média (\%) & ASTM A 897 (\%) \\
\hline $\mathrm{C} . \mathrm{E}$ & 4,43 & 4,42 & 4,46 & 4,44 & 4,3 a 4,6 \\
$\mathrm{C}$ & 3,6600 & 3,6500 & 3,6700 & 3,6600 & $3,60 \pm 0,20$ \\
$\mathrm{Si}$ & 2,2400 & 2,2600 & 2,3000 & 2,2667 & $2,50 \pm 0,20$ \\
$\mathrm{Mn}$ & 0,3000 & 0,2980 & 0,2860 & 0,2947 & $0,35 \pm 0,05$ \\
$\mathrm{P}$ & 0,0846 & 0,0674 & 0,0816 & 0,0779 & $<0,04$ \\
$\mathrm{~S}$ & 0,0097 & 0,0088 & 0,0098 & 0,0094 & $<0,02$ \\
$\mathrm{Cr}$ & 0,0208 & 0,0174 & 0,0254 & 0,0212 & $<0,10$ \\
$\mathrm{Ni}$ & 0,0085 & 0,0083 & 0,0082 & 0,0084 & $<2,00$ \\
$\mathrm{Mo}$ & 0,0009 & 0,0010 & 0,0005 & 0,0008 & $<0,30$ \\
$\mathrm{Al}$ & 0,0119 & 0,0142 & 0,0118 & 0,0126 & $<0,05$ \\
$\mathrm{Cu}$ & 0,8160 & 0,7400 & 0,7720 & 0,7760 & $<0,80$ \\
$\mathrm{Ti}$ & 0,0093 & 0,0102 & 0,0094 & 0,0096 & $<0,04$ \\
$\mathrm{~V}$ & 0,0023 & 0,0018 & 0,0022 & 0,0021 & $<0,10$ \\
$\mathrm{~Pb}$ & 0,0002 & 0,0002 & 0,0002 & 0,0002 & $<0,02$ \\
$\mathrm{Sn}$ & 0,0021 & 0,0029 & 0,0021 & 0,0024 & $<0,02$ \\
$\mathrm{Mg}$ & 0,0347 & 0,0374 & 0,0353 & 0,0358 & $0,04 \pm 0,005$ \\
$\mathrm{Fe}$ & 92,8 & 92,9 & 92,8 & 92,8 & - \\
$\mathrm{W}$ & 0,0028 & 0,0028 & 0,0028 & 0,0028 & - \\
\hline
\end{tabular}

Segundo Cardoso, Israel e Strohaecker (2010) o carbono equivalente é um indicador que confere a combinação efetiva dos elementos silício e fósforo influenciados com o carbono. As fusões apresentaram valores para o carbono equivalente muito próximos entre elas, variando de 4,42 a 4,46, definindo as ligas ligeiramente hipereutéticas.

\section{Análise metalográfica}

\section{Estado bruto de fusão}

As imagens das amostras brutas de fusão foram obtidas pela micrografia dos corpos de prova preparados sem sofrerem tratamento térmico. Essas imagens foram fornecidas em laudos emitidos pelo próprio laboratório de metalurgia da Fundição Batatais. É mostrado na Figura 1 a micrografia, com aumento de 100x, correspondente ao primeiro corpo de prova da primeira fusão, uma matriz composta na maioria pela fase perlita, com grafitas tipo I, II e III de tamanhos de 6 a 7, com grau de esferoidização de 85,6\%.

As propriedades das microestruturas analisadas foram descritas em função dos corpos de provas e suas fusões, e estão ilustradas no gráfico da Figura 2. 
Figura 1 - Microestrutura bruta de fusão: fusão 1 - CP1. (100x)

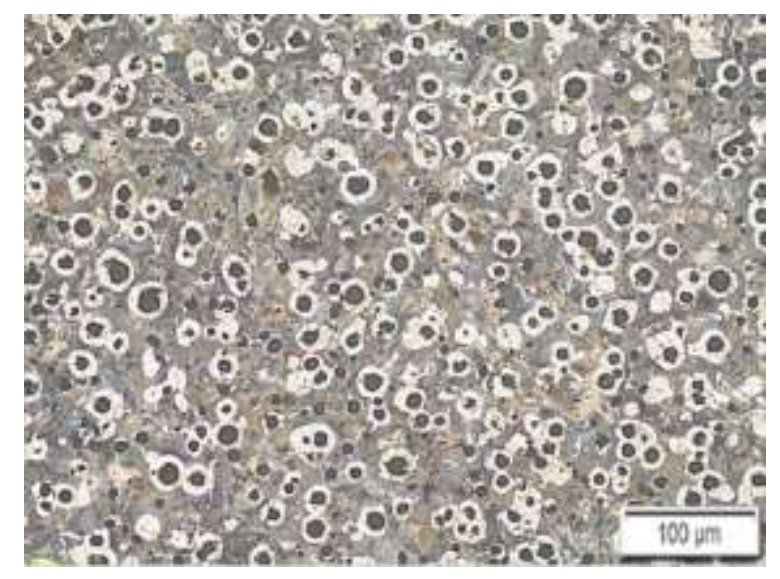

Figura 2 - Propriedades microestruturais do material bruto de fusão

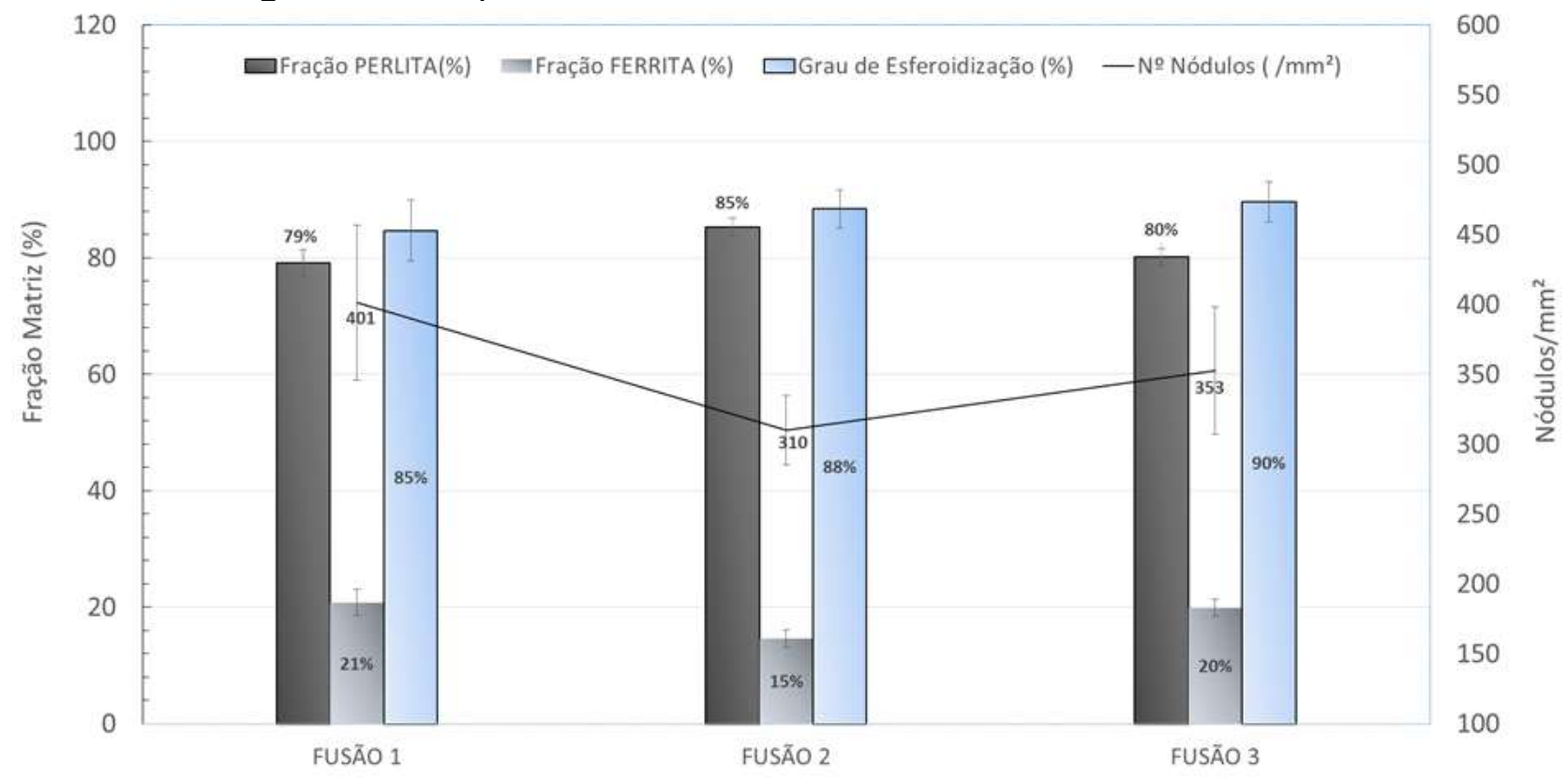

O material bruto de fusão possui uma matriz predominantemente perlítica com média de $81,54 \%$ de sua fração volumétrica, com desvio padrão de 3,31\% entre as fusões. O grau de esferoidização médio apresentado foi de $87,6 \%$ com desvio padrão de $1,08 \%$. A contagem de nódulos médio foi de 354,67 nódulos por $\mathrm{mm}^{2}$, os quais tiveram um desvio padrão de 45,66 nódulos. Assim, é possível concluir que o material bruto de fusão apresentou as propriedades mínimas exigidas pela norma ASTM A 897/A897M-16, descritas como valores mínimos de 100 nódulos $/ \mathrm{mm}^{2}$ e grau de esferoidização mínimo de $80 \%$, o que aprova o material para o processo de tratamento térmico por austêmpera. A matriz predominantemente perlítica, favorece a solubilização do carbono na austenita durante a etapa de austenitização e a grande quantidade de nódulos, reduz as segregações nos contornos de células eutéticas, prejudiciais à tenacidade do material, além de ser uma fonte de carbono para a austenita durante a fase de austenitização. 


\section{Estado após austêmpera}

As microestruturas analisadas após o processo de austêmpera foram obtidas pela amostra retirada do corpo de prova de tração após ensaio. As imagens apresentadas na Figura 3 ("a" e "b") descrevem a microestrutura resultante da análise do quinto corpo de prova da primeira fusão, após tratamento térmico e com um aumento de 100x e 500x, respectivamente.

Figura 3 - Microestruturas após austêmpera: fusão 1 - CP5 - a) (100x); b) (500x)

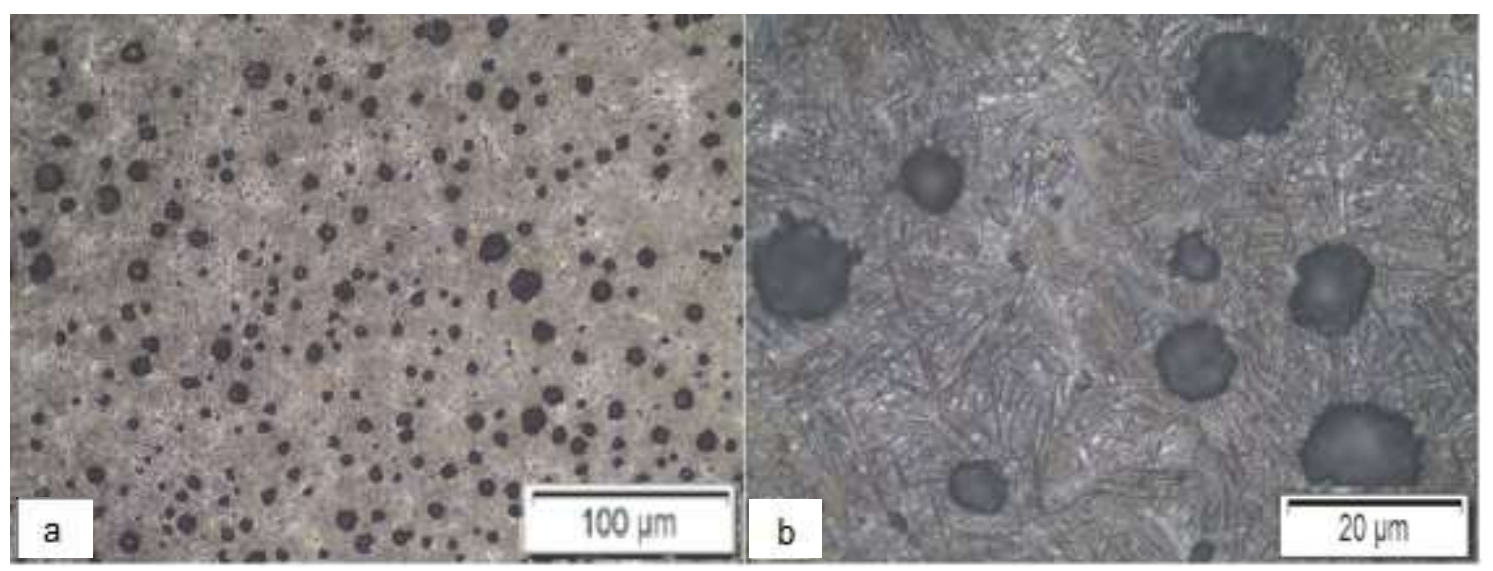

O processo de austêmpera permanecendo por $2 \mathrm{~h}$ a uma temperatura de $290^{\circ} \mathrm{C}$ resultou em uma microestrutura prevalecente de uma mistura de ferrita acicular e austenita. Mantendo uma proporção e características semelhantes entre as amostras dos corpos de prova obtidos e das fusões analisadas.

\section{Propriedades mecânicas}

A Figura 4 mostra os resultados obtidos nos testes de tração, contendo valores de limite de resistência, limite de escoamento e alongamento. Os resultados estão descritos em função dos corpos de provas, comparando-se o estado bruto de fusão e o austemperado, para cada fusão analisada.

Vale ressaltar que de acordo com a norma SAE J434 (2017) o material bruto de fusão da classe D5504 está dentro dos parâmetros mínimos de tração para a classe (L.R > 550 MPa; L.E. > $380 \mathrm{MPa}$; Alongamento > 4\%), conforme valores ilustrados no gráfico da Figura 4. E como pode-se observar, após o tratamento térmico de austêmpera, em média, 0 material atingiu a classificação Grade 3, conforme norma ASTM A 897/A897M-16.

O ensaio de tração evidencia que o processo de austêmpera provocou um aumento médio de $95 \%$ no limite de resistência e de $142 \%$ no limite de escoamento. E uma redução média de $60 \%$ no alongamento.

De acordo com o estudo realizado por Balzer e Oliveira (2002), o tempo e temperatura de permanência do tratamento térmico influenciam significativamente na proporção da fração microestrutural de ferrita acicular e austenita retida resultante. Assim, variações do processo podem provocar alteração da ferrita acicular nucleada a partir dos contornos de grãos da austenita e dos nódulos de grafita, como também sugerem a possibilidade do aparecimento de martensita para períodos curtos, com menor quantidade 
de austenita retida, indicando possível formação de carbonetos para períodos longos. Assim, verifica-se que esses fatores, juntamente com a presença de grafitas do tipo III, afetam diretamente nos resultados de tração e dureza observados. Para um período de $2 \mathrm{~h}$ de processo de austêmpera pode-se então observar uma permanência de valores elevados de L.R. e L.E., porém valores reduzidos de alongamento.

Figura 4 - Ensaio de tração

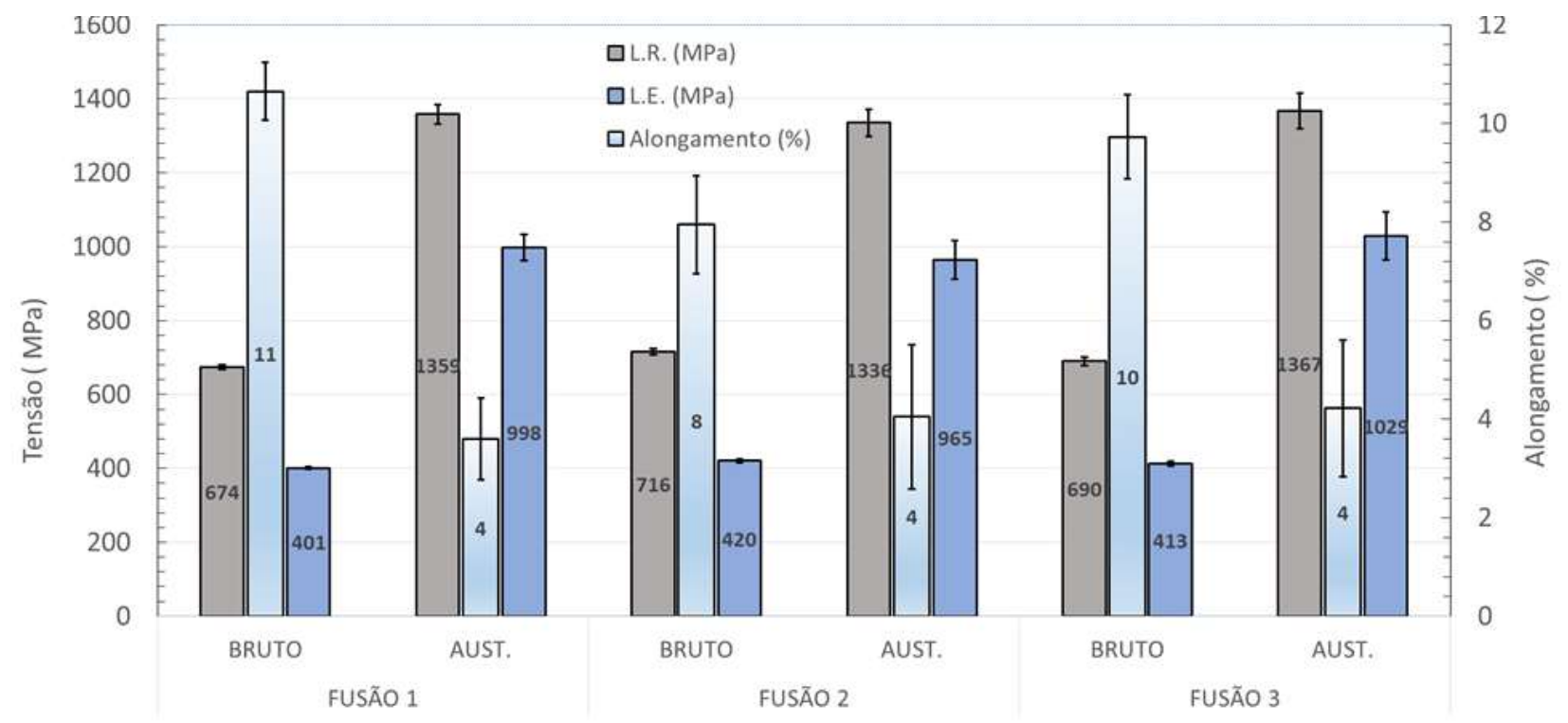

Para Boneti (2014), após análise de difração de raios X em várias amostras, que variaram as temperaturas de austenitização e de austêmpera, a quantidade das intensidades difratadas dos picos de austenita aumentam para maiores temperaturas de austenitização e austêmpera, sendo a temperatura de austêmpera a que possui maior influência sobre a quantidade de austenita retida.

Assim, como a austenita retida contribui para a ductilidade do material, seria essencial analisar a fração de austenita retida / ferrita acicular para identificar se o baixo alongamento atingido foi pela baixa porção de austenita ou se há presença de carbonetos de solidificação nas regiões intercelulares.

A Figura 5 apresenta o gráfico com o resultado do ensaio de dureza Brinell e impacto de Charpy em função das fusões obtidas e do estado bruto de fusão e austemperado.

Observou-se um aumento médio de aproximadamente $74 \%$ no valor da dureza apresentada nos materiais após o tratamento térmico. O valor apresentado na norma ASTM A 897/A897M-16 para a Grade 3 atingida é de $341 \mathrm{HB}$ a $444 \mathrm{HB}$ e a média apresentada neste estudo foi de 364HB.

Esse aumento da dureza também é influenciado pela alteração da matriz metálica, de ferrita/perlita para uma estrutura composta de austenita retida e ferrita acicular. Essa composição favorece o aparecimento de compostos enrijecidos como martensitas e carbonetos, influenciados por temperatura e tempo de processos como tensionamento da matriz.

O gráfico da Figura 5 com os resultados do ensaio de impacto Charpy dos materiais antes e após o tratamento térmico, foram obtidos em amostras sem entalhes e em uma temperatura ambiente de $21^{\circ} \mathrm{C}$. 
Figura 5 - Ensaio de dureza Brinell e impacto de Charpy

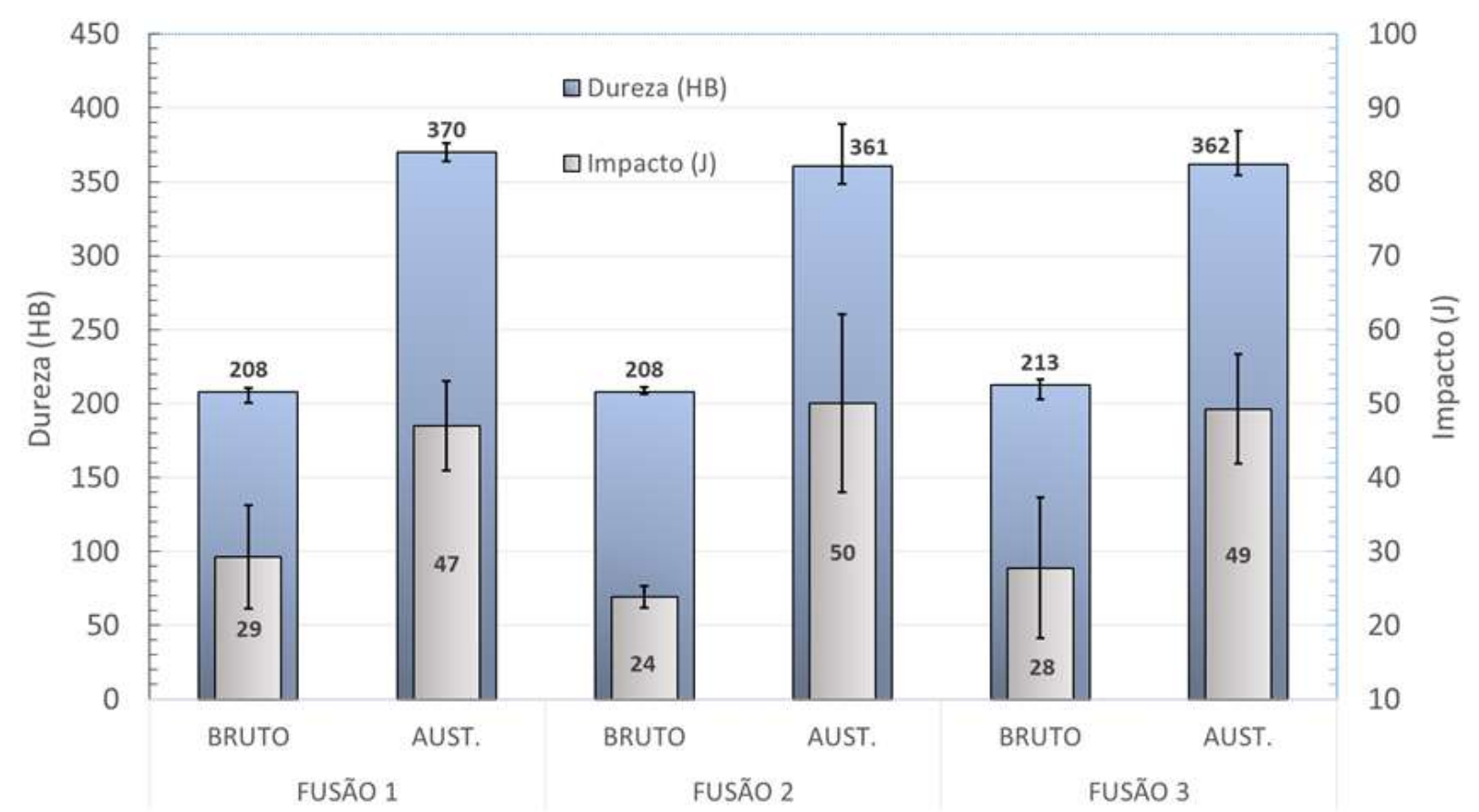

Os resultados obtidos no ensaio de impacto, revelaram um aumento significativo de aproximadamente $82 \%$ na média da energia do impacto, ou seja, após o tratamento térmico o material aumentou sua capacidade de absorver energia, porém não o suficiente para atender à norma. Para a norma SAE J434 (2017), o ferro fundido nodular da classe D5504 deveria ser capaz de absorver 40J, o que não foi observado para as amostras do material sem tratamento. Para a norma ASTM A 897/A897M-16, a Grade 3 analisada em questão, a exigência é que o material consiga suportar $60 \mathrm{~J}$, valor esse também não atingido.

Como os valores de alongamento e impacto foram insuficientes comparados aos valores exigidos em normas, tanto para o bruto de fusão quanto o material austemperado, foram refeitas as análises metalográficas para as amostras, com melhor verificação e contagens, as quais apresentaram quantidade significativa de grafitas tipo III, em fração volumétrica média de $30 \%$. Essas grafitas irregulares que, devido a formas degeneradas diminuem a capacidade de alongamento e absorção de impacto, não foram evidenciadas em primeira análise. Assim, pode-se observar uma nova configuração de características microestruturais após refeitas as análises, com uma correlação mais próxima às propriedades mecânicas apresentadas, o que sugere melhorias no processo de nodularização e inoculação buscando melhorar o grau de nodularização e menores quantidades de grafita tipo III.

\section{CONCLUSÕES}

Com base nos resultados observados, pode-se concluir que os objetivos foram alcançados. A liga de ferro nodular SAE J434 - D5504 ao passar por um processo de tratamento térmico por austêmpera e obedecendo a janela de tratamento correta, apresentou mudanças na microestrutura e, consequentemente, evoluiu para alterações significativas nas propriedades mecânicas.

A liga de ferro nodular SAE J434 - D5504 austemperado atingiu a classificação 
Grade 3 para as propriedades mecânica, ou seja, após o tratamento térmico, a liga melhorou sua capacidade resistiva à tração, mas reduziu a ductilidade relativa.

Os valores da dureza e da energia de impacto aumentaram com a austêmpera. Porém, o aumento da energia de impacto não foi suficiente para atingir os valores mínimos exigidos pela norma, tanto para o bruto de fusão quanto o material austemperado.

Ao analisar as microestruturas foi observado grande presença de grafita tipo III, o que pode justificar a queda dos valores de impacto após tratamento térmico, e o baixo valor de alongamento sugerindo assim atenção no processo de nodulização e nucleação das grafitas.

\section{REFERÊNCIAS}

ABIFA. Associação Brasileira de Fundição. Desempenho do Setor de Fundição Dezembro/2016, 2017. Disponível em: http://www.abifa.org.br/wpcontent/uploads/2017/01/12DESDEZEMBRO2016.pdf. Acesso em: 13 dez. 2017.

ASTM. American Society for Testing and Materials. A247-17: Standard Test Method for Evaluating the Microstructure of Graphite in Iron Castings, ASTM International, West Conshohocken, PA, 2017, Disponível em: https://doiorg.ez33.periodicos.capes.gov.br/10.1520/A0247-17. Acesso em: 31 out. 2017.

ASTM. American Society for Testing and Materials. A327/A327M-11: Standard Test Methods for Impact Testing of Cast Irons, ASTM International, West Conshohocken, PA, 2017. Disponível em: https://doi-

org.ez33.periodicos.capes.gov.br/10.1520/A0327_A0327M. Acesso em: 31 out. 2017.

ASTM. American Society for Testing and Materials. A897/A897M-16: Standard Specification for Austempered Ductile Iron Castings, ASTM International, West Conshohocken, PA, 2016. Disponível em: https://doiorg.ez33.periodicos.capes.gov.br/10.1520/A0897_A0897M-16. Acesso em: 31 out. 2017.

ASTM. American Society for Testing and Materials. E7-17: Standard Terminology Relating to Metallography, ASTM International, West Conshohocken, PA, 2017. Disponível em: https://doi-org.ez33.periodicos.capes.gov.br/10.1520/E0007-17. Acesso em: 31 out. 2017.

ASTM. American Society for Testing and Materials. E10-17: Standard Test Methods for Brinell Hardness of Metallic Materials, ASTM International, West Conshohocken, PA, 2017. Disponível em: https://doi-org.ez33.periodicos.capes.gov.br/10.1520/E0010-17. Acesso em: 31 out. 2017.

ASTM. American Society for Testing and Materials. E407-07 e1: Standard Practice for Microetching Metals and Alloys, ASTM International, West Conshohocken, PA, 2015. Disponível em: https://doi-org.ez33.periodicos.capes.gov.br/10.1520/E0407-07R15E01. Acesso em: 31 out. 2017.

BALZER, M. E.; OLIVEIRA, C. A. S. Determinação da Janela de Processo de Um ferro Fundido Nodular Austemperado (ADI) sem Adição de Elementos de Liga Através de 
Ensaios Mecânicos e Metalográficos. In: Congresso Brasileiro de Engenharia e Ciência dos Materiais, Natal, 2002.

BONETI, L. L. T. Influência das temperaturas de austenitização e austêmpera na microestrutura e propriedades de tração de um ferro fundido nodular. Dissertação (Mestrado em Engenharia e Ciência de Materiais) - Universidade Estadual de Ponta Grossa, Ponta Grossa, 2014.

BUCHLI, M. Análise de manufatura e de produto para a utilização do ferro fundido austemperado ADI grau 3 em eixo comando de válvulas de motores Diesel.

Dissertação (Mestrado Profissional em Engenharia Mecânica) - Faculdade de Engenharia Mecânica, Universidade Estadual de Campinas, Campinas, 2010.

CARDOSO, P. H. S.; ISRAEL, C. L.; STROHAECKER, T. R. Comparative study of quenched and austempered ductile cast irons. Revista Estudos Tecnológicos em Engenharia, v. 6, n. 3, p. 140-148, 2010.

CARMO, D. J. Desenvolvimento do processo tecnológico de fabricação de peças em ferro fundido nodular austemperado (ADI). Dissertação (Mestrado em Engenharia Metalúrgica e de Minas) - Universidade Federal de Minas Gerais, Belo Horizonte, 2003.

HUPALO, M. F.; BALZER, M. E.; WARMLING, G. Avaliação da austemperabilidade de um ferro fundido nodular de classe perlítica (FE-70002) em corpos de prova com $50 \mathrm{~mm}$ de espessura. In: Congresso Brasileiro de Engenharia e Ciência dos Materiais. Foz do Iguaçu, PR, 2006.

MACHADO, M. A. Desenvolvimento Dos Parâmetros De Tratamento Térmico De Ferro Fundido Nodular Austemperado ASTM987 Grau II. Dissertação (Mestrado em Engenharia de Minas, Metalúrgica e de Materiais) - Escola de Engenharia, Universidade Federal do Rio Grande do Sul, Porto Alegre, 2007.

MARTINEZ, J. A. B. Comparação da resistência ao desgaste por fadiga de contato de engrenagens fabricadas em aço AISI 4140 e ferro fundido nodular austemperado. Dissertação (Engenharia Mecânica e de Materiais) Universidade Tecnológica Federal do Paraná, Curitiba, 2011.

NOGUEIRA, E. A. S. Simulação computacional da deformação superficial induzida em corpos-de-prova para ensaio de fadiga em ferro fundido austemperado.

Dissertação (Mestrado em Engenharia Metalúrgica e de Minas) - Universidade Federal de Minas Gerais, Belo Horizonte, 2011.

PIMENTEL, A. S. O.; GUESSER, W. L. Tratamento térmico de austêmpera em ferro fundido nodular com adições de nióbio e de cromo. Matéria, v. 22, n. 2, e11816, 2017.

SAE J434. Society of Automotive Engineers. Automotive Ductile Iron Castings, SAE International, 2017. Disponível em: <http://standards.sae.org/J434_201712. Acesso em: 21 fev. 2018. 